\title{
BRAF mutations in cutaneous melanoma: no correlation with histological prognostic factors or overall survival
}

Primeira submissão em 22/04/10 Última submissão em 17/09/10 Aceito para publicação em 29/09/10 Publicado em 20/12/10

\section{Mutações BRAF em melanomas cutâneos: nenhuma correlação com fatores prognósticos e sobrevida global}

Juliana Elizabeth Jung'; Thomas M. Falk²; Martina Bresch³; Jorge Eduardo Fouto Matias4; Almut Böer ${ }^{5}$

key words
Proto-oncogene proteins
BRAF
Proto-oncogene proteins
c-Kit
Malignant melanoma

\section{abstract}

Introduction: Molecular biology techniques allow identification of molecular markers such as BRAF and c-Kit gene mutations in melanomas. Studies on genetic alterations in melanomas of South-American patients are sparse. Objectives: To identify the incidence of BRAF and c-Kit gene mutations in primary cutaneous melanomas in Brazilian patients and to evaluate pathogenetic and prognostic implications of these mutations correlating them with clinical and histopathological data. Material and methods: Ninety-six surgical specimens of primary cutaneous melanoma and 15 corresponding metastasis were analyzed using TaqMan Real-Time polymerase chain reaction (PCR) assays. Results: In comparison with the medical literature, a relatively low frequency of BRAF mutation in primary (39\%) and metastatic (40\%) melanomas and complete absence of c-Kit gene mutations were demonstrated. BRAF mutations arose at an early stage during melanoma progression and were not involved in the transition of thin $(\leq 1 \mathrm{~mm})$ to thick $(>1 \mathrm{~mm})$ melanomas. BRAF mutations are related to patients' younger age and to the pattern of sun exposure, although there was no correlation with any histological prognostic factor or overall survival. Conclusion: The identification of both BRAF and c-Kit mutation is not a suitable prognostic indicator in the Brazilian population. Moreover, the relatively low frequency of BRAF mutations brings into question if it actually plays a key role in melanoma pathogenesis.

\section{resumo}

Introdução: Técnicas de biologia molecular permitem a identificação de marcadores moleculares como mutações dos genes BRAFe c-Kit em melanomas. Estudos de alterações genéticas em pacientes sul-americanos são escassos. Objetivos: Identificar a incidência de mutações dos genes BRAF e c-Kit em melanomas cutâneos primários em uma série de pacientes brasileiros e avaliar as implicações patogenéticas e prognósticas dessas mutações, correlacionando-as com dados clínicos e histopatológicos. Material e métodos: Noventa e seis espécimes cirúrgicos de melanomas cutâneos e 15 metástases correspondentes foram analisados por meio da técnica TaqMan Real-Time polymerase chain reaction (PCR). Resultados: Uma frequência relativamente baixa de mutações BRAF em melanomas cutâneos primarios (39\%) e metastáticos (40\%) em comparação com os dados da literatura e ausência de mutações c-Kit foi demonstrado. Mutações BRAF surgiram em um estágio inicial da progressão do melanoma e não foram envolvidas na transição de melanomas finos (< $1 \mathrm{~mm}$ ) para grossos (> $1 \mathrm{~mm}$ ). Essas mutações estavam presentes em pacientes mais jovens e se correlacionaram com o padrão de exposição solar dos pacientes estudados, mas não houve correlação com nenhum fator prognóstico histológico ou sobrevida global dos mesmos. Conclusão: A identificação de ambas as mutações (BRAF e c-Kit) não servem como indicadores de prognóstico na população brasileira. Além disso, a baixa frequência de mutações BRAF encontrada neste estudo nos faz questionar se essa mutação realmente tem papel-chave na patogênese do melanoma.

\section{unitermos}

Proteínas protooncogênicas BRAF

Proteínas protooncogênicas c-Kit

Melanoma maligno

\footnotetext{
1. Doutora em Clínica Cirúrgica pela Universidade Federal do Paraná (UFPR).

2. Doutor em Biologia pela Universidade de Hamburgo (Alemanha); biólogo do setor de Biologia Molecular do Instituto Dermatologikum Hamburg (Alemanha).

3. Bióloga do Laboratório de Anatomia Patológica do Instituto Dermatologikum Hamburg (Alemanha).

4. Doutor em Cirurgia Digestiva pela Universidade de Montpellier (França); professor adjunto da Universidade Federal do Paraná (UFPR).

5. Doutora em Dermatologia pela Universidade de Frankfurt (Alemanha); dermatopatologista do Instituto Dermatologikum Hamburg (Alemanha).
} 


\section{Introduction}

Cutaneous melanoma is one of the most aggressive malignant neoplasms and its incidence is increasing, especially among the white population ${ }^{(26)}$. Clinical and histopathological data of a primary cutaneous melanoma provide useful prognostic information; however, the clinical course of an individual neoplasm is currently unpredictable and additional factors to predict its evolution are necessary ${ }^{(19)}$.

Molecular biology techniques have recently permitted the identification of molecular markers involved in melanoma pathogenesis include cell-cycle regulators, such as the BRAF gene and the proto-oncogene c-Kit. Mutations on the BRAF gene located on chromosome $7 q$ are the most frequent mutations found in human melanomas. The BRAF gene encodes a serine/threonine kinase downstream of RAS in the RAS/RAF/MAPK pathway that is involved in transduction of mitogenic signals from membrane receptors to the nucleus ${ }^{(5,15)}$. The c-Kit receptor plays a critical role in melanocyte physiology, influencing melanogenesis, proliferation, migration, and survival of the pigmentproducing cells ${ }^{(2,29)}$.

Little information is found in the literature about BRAF mutation in cutaneous melanomas of South-American patients. None of the studies currently available attempted to correlate all histological and clinical prognostic parameters as well as outcome of cutaneous melanomas with concurrent examination of BRAF and c-Kit mutations. We studied 96 Brazilian patients with melanoma for both, BRAF and c-Kit mutations, and correlated molecular data with clinical and histopathological findings, with molecular data of corresponding metastases (15 cases), and outcome.

\section{Material and methods}

\section{Melanoma specimens}

This study was based on 96 formalin-fixed and paraffinembedded surgical specimens from patients of both sexes and various ages with the diagnosis of primary cutaneous melanoma. The patients had been diagnosed between 2000-2004 at the Erasto Gaertner Hospital in Curitiba, state of Paraná, Brazil. Each sample of the primary tumor belonged to only one patient. This study has full current institutional ethical committee approval. The slides from the patients were reviewed independently by two dermatopathologists to confirm the diagnosis of cutaneous melanoma and to determine the Breslow index. The diagnosis of cutaneous melanoma was based on well-established criteria ${ }^{(1,16)}$.

The following data was also tabulated: Clark level, number of mitoses, presence of ulceration, presence of regression, and satellitosis. The clinical data of the patients included in this study were obtained from their records and tabulated to evaluate sex, age, site of the lesion, and clinical outcome.

Regarding the site of the primary lesion, we applied the same parameter that Maldonado et al. used in their study, dividing the melanomas in two groups: those occurring on skin subject to intermittent sun exposure or rarely exposed skin (trunk, superior members, inferior members, and acral) and those occurring on chronically sun damaged skin such as the head and neck ${ }^{(15)}$.

The patient survival was evaluated according to Francken ${ }^{(9)}$ and the patients were divided into the following two groups:

- favorable outcome - alive without evidence of melanoma or death of other cause;

- unfavorable outcome - alive with evidence of melanoma (relapse, local or distant) and death of melanoma.

Table shows the distribution of clinical and histopathological data from the 96 patients studied.

\section{Molecular genetic analysis}

\section{DNA isolation}

Tumor material (about $1 \mathrm{~mm}^{2}$ ) was semi-microdigested from $10 \mu \mathrm{m}$ sections using $1-2 \mu \mathrm{l}$ of digestion buffer $(10 \mu \mathrm{l}$ Proteinase K/90 $\mu \mathrm{l}$ 1x PCR buffer; QIAGEN) placed at the area of the section covered by the tumor only. The digestion area of the section covered about $1 \mathrm{~mm}^{2}$. The complete area covered by the tumor was at least three fold larger. The same procedure was also used to prepare DNA samples from non-tumor sites from all individual samples studied. Pathological review was performed on all specimens using $\mathrm{HE}$-stained slides for comparison. After about 15 minutes the digestion buffer from the sections $(1-2 \mu \mathrm{l})$ containing the tumor or non-tumor tissue was transferred into $1,5 \mathrm{ml}$ Eppendorf tubes and digestions of these crude extracts were subsequently completed within a total volume of $100 \mu \mathrm{l}$ incubated at $55^{\circ} \mathrm{C}$ for at least 24 hours. After Proteinase $\mathrm{K}$ inactivation $\left(95^{\circ} \mathrm{C} / 8 \mathrm{~min}\right.$.) these tumor DNA samples and non-tumor DNA samples were used directly in subsequent molecular analyses. Pathological review was performed on all specimens using HE-stained slides for comparison. 


\section{Table Characteristics' of the patients $(n=96)$}

Sex

Female

Male

Age (years)

Range

Mean

$17-83$

Median

52.9

Site (sun exposure)

Intermittent

Chronic

$79(82.2 \%)$

$17(17.7 \%)$

Breslow (mm)

$\begin{array}{ll}\text { Range } & 0.2-15 \\ \leq 1 \mathrm{~mm} & 27(28.1 \%) \\ >1 \mathrm{~mm} & 69(71.9 \%) \\ \text { Clark } & \\ \text { I } & 0 \\ \text { II } & 41(42.7 \%) \\ \text { III } & 24(25 \%) \\ \text { IV } & 20(20.8 \%) \\ \text { V } & 11(11.4 \%) \\ \text { Mitosis } & \\ <6 & 84(93.3 \%) \\ \geq 6 & 12(12.5 \%)\end{array}$

Ulceration

$\begin{array}{ll}\text { Present } & 46(47.9 \%) \\ \text { Absent } & 50(52 \%)\end{array}$

Regression

$\begin{array}{ll}\text { Present } & 42(43.7 \%) \\ \text { Absent } & 54(56.2 \%)\end{array}$

$54(56.2 \%)$

Satellitosis

$\begin{array}{ll}\text { Present } & 11(11.4 \%) \\ \text { Absent } & 85(88.5 \%)\end{array}$

Prognosis

Favorable

$65(67.7 \%)$

Unfavorable

$31(32.2 \%)$

Follow-up (years)

$\begin{array}{ll}\text { Range } & 0.8-6 \\ \text { Mean } & 3.1 \\ \text { Median } & 3.4\end{array}$

BRAF mutation - primary tumor

Total

$\begin{array}{ll}\text { Present } & 38(39.5 \%) \\ \text { Absent } & 58(60.4 \%)\end{array}$

Breslow $<1 \mathrm{~mm}$

Present

Absent

$12(44.5 \%)$

Breslow > 1mm

Present

Absent

\section{BRAF mutation}

Primarily, TaqMan RT-PCR detection was used to identify BRAF V599E mutations modified according to Smyth

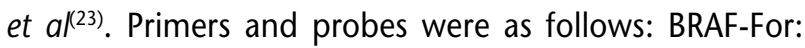
5'-CATGAAGAC CTCACAGTAAAAATAGGTGAT-3'; BRAFRev: 5'-GGATCCAGACA ACTGTTCAAACTGA-3'; HEX-5'CCATCGAGATTTCACTGTAG-3'-TAMRA (BRAF- WT); FAM5'-CCATCGAGATTTCTCTGTAG-3'-TAMRA (BRAF-V600E -MUT). Amplification and RT-PCR analysis was performed on an IQ5-Cycler (BioRad Laboratories, Inc.) for 50 cycles $\left(95^{\circ} \mathrm{C}\right.$ for $3 \mathrm{~min}[1 \mathrm{cycle}] ; 5^{\circ} \mathrm{C}$ for $15 \mathrm{sec} ., 5^{\circ} \mathrm{C}$ for $1 \mathrm{~min}$ [50 cycles]). For Real-Time PCR detection of mutation V600E the size of the amplicon was about $120 \mathrm{bp}$. For conventional end point PCR and subsequent sequencing the size of the BRAF exon 15 amplicon was about 235 bp. RT-PCR reactions were carried out in $25 \mu$ reaction mixtures: $1 \times$ IQ Supermix (BioRad Laboratories, Inc.), $500 \mathrm{nM}$ of each primer, $200 \mathrm{nM}$ of each probe and about 40-90 ng total DNA (final concentrations). Each sample was analysed twice. Results of RT-PCR analyses were also verified by direct sequencing of BRAF exon 15 PCR products (6 BRAF V599E positive and 20 BRAF V599E negative samples). Amplification of exon 15 was carried out according to Davis et al.(5): exon 15- For: 5'-TCATAATG CTTGCTCTGATAGGA-3'; exon 15Rev: 5'-GGCCAAAAATTTAATCAGTGGA-3'. PCR reactions were performed in $50 \mu \mathrm{l}$ reaction mixtures (1x reaction buffer, HotStarTaq QIAGEN; $3.5 \mathrm{mM} \mathrm{MgCl}{ }_{2} ; 1.2 \mu \mathrm{M}$ of each primer; about $40-60 \mathrm{ng}$ total DNA; $200 \mu \mathrm{M}$ of each dNTP; 2.5 units HotStarTaq DNA polymerase, QIAGEN). The thermal profile was: $1.95^{\circ} \mathrm{C} / 15 \mathrm{~min}(1 \mathrm{cycle}) ; 2.94^{\circ} \mathrm{C} / 20$ sec; $56^{\circ} \mathrm{C} / 30 \mathrm{sec} ; 72^{\circ} \mathrm{C} / 30 \mathrm{sec}\left(50\right.$ cycles); $3.72^{\circ} \mathrm{C} / 8 \mathrm{~min}$ (1 cycle). PCR products were purified (GFX PCR DNA and Gel Band Purification Kit, GE Healthcare, UK) and sequenced on an ABI 377 automated sequencer (Applied Biosystems) using the BigDye Terminator Cycle Sequencing Chemistry (Applied Biosystems). Sequences were further processed using BioEdit version 5.0.9 and identified using the NCBI BLAST search. Samples for which insufficient, no or only BRAF-V599E -WT fluorescence signals (HEX) were obtained by RT-PCR assays were amplified according to Davis et al. and subsequently sequenced (BRAF exon 15) ${ }^{(5)}$.

\section{C-Kit mutation}

A novel TaqMan RT-PCR assay was used to identify C-Kit L576P mutations. Primers and probes were developed using Primer3Plus: C-Kit-For: 5'-CAGTGGAAGGTTGTTGA GGA -3'; C-Kit-Rev: 5'-GCCTGTTTCTGGGAAACTCC -3'; HEX-5'CCCAACACAA CTTCCTTATGATC -3'-TAMRA (C-KIT-WT); 
FAM-5'-CCCAACACAACCTCCTTATGA TC -3'-TAMRA (C-KIT-L576P-MUT). Product size: 100 bp. Amplification and RT-PCR analysis was performed as outlined above with slight modifications (annealing temperature: $61^{\circ} \mathrm{C} ; 400 \mathrm{nM}$ of each primer, $250 \mathrm{nM}$ of each probe-final concentrations). Results of RT-PCR analyses were also verified by direct sequencing of some C-Kit PCR products $(n=12)$. Samples for which no or insufficient fluorescence signals were obtained by RT-PCR assays (WT- as well as MUT-Signals) were amplified using the above primers and subsequently sequenced. A C-Kit L576P positive adenocarcinoma sample served as positive control.

\section{Statistical analysis}

Fisher exact test was used to analyze the data. A $p$-value $<0.05$ was considered statistically significant. Survival was estimated by the Kaplan-Meier curve.

\section{Results}

\section{Frequency of BRAF mutations}

BRAF exon 15 mutations were present in 39\% (38 of 96) specimens of primary cutaneous melanoma and the Val599Glu substitution accounted for $92.1 \%$ (35 of 38) of all mutations. In ten of our cases, the mutations were also investigated in normal cells from the same individual, and they were not present, indicating that they were somatically acquired. Three cases $(7.89 \%)$ presented the nucleotide substitution GT1795-96AA, which changed the wild-type codon GTG (valine) to AAG (lysine), at position 599 (V599K). Val599Glu mutated BRAF has been shown to have a higher kinase activity than wild type BRAF, and both the Val599Glu and Val599Lys changes render BRAF more potent in inducing transformation ${ }^{(8)}$. We also identified loss of heterozygosity in three primary cutaneous melanomas and one metastatic melanoma, all at the position V599E. In total, in only four samples, amplification failed, namely in two samples of primary lesions and in two of metastatic lesions most likely due to unbuffered formalin fixation of the specimens.

\section{Correlation of BRAF mutations with growth phase and tumor thickness}

Melanomas with thickness (Breslow index) inferior or equal to $1.0 \mathrm{~mm}$ were classified as "thin melanomas" and the others were considered "thick melanomas"(3).
We applied this classification in this study because we hypothesized that the differentiation between thin and thick melanomas could enable us to determine at what stage during melanoma progression the mutations occurred. In thin melanomas, BRAF mutation was present in 12 cases (44.4\%) and in thick melanomas, in 26 cases (37.7\%). There was no significant statistical difference between these two groups considering the presence of the mutation $(p>0.05)$. Our results found BRAF mutations to be frequent in primary melanomas, including both thin and thick melanomas, (Figure1) which implies that these mutations can occur early in the progression process of melanoma.

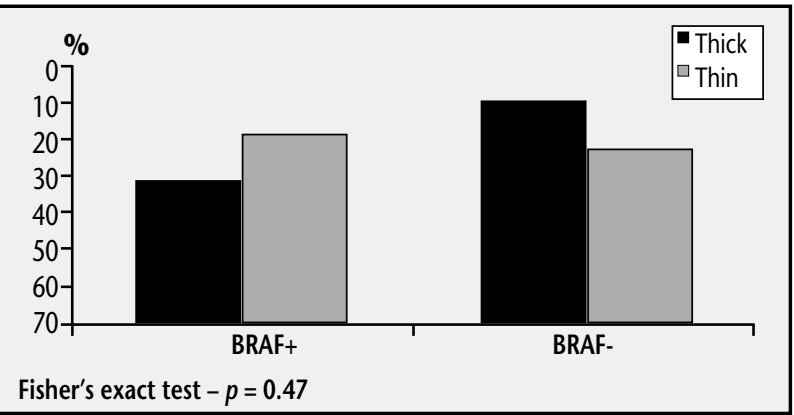

Figura 1 - Frequency of BRAF mutations in thin compared with thick melanomas

\section{BRAF mutations in pairs of primary tumors and corresponding metastases}

In 15 cases, both primary tumour and metastases were analysed and BRAF mutation was found in 6 cases (40\%), both in primary and metastatic tumors. In four cases, the paired primary and metastatic lesions had the same BRAF genotype. Considering the frequency of BRAF mutations in the primary lesions (39\%) and in the metastatic lesions (40\%) there was no significant statistical difference between the two groups $(p>0.05)$.

\section{Correlation of BRAF mutations with clinical data}

In the present study we found that the melanoma specimens with BRAF mutations belonged to younger patients when compared to those without the mutation $(45.6+16.2$ years versus $57.8+15.8$ years $-p<0.001)$. Our data showed no statistically significant difference concerning the sex of the patients, with similar proportion of BRAF mutation in both sexes $(p=0.83)$. When we compared lesions arising in areas of intermittent sun exposure with those of chronic sun exposure, we observed a significant predominance of BRAF mutations in lesions arising in intermittently sun-exposed skin compared with those arising on continually exposed skin; $p<0.001$ (Figure 2). 


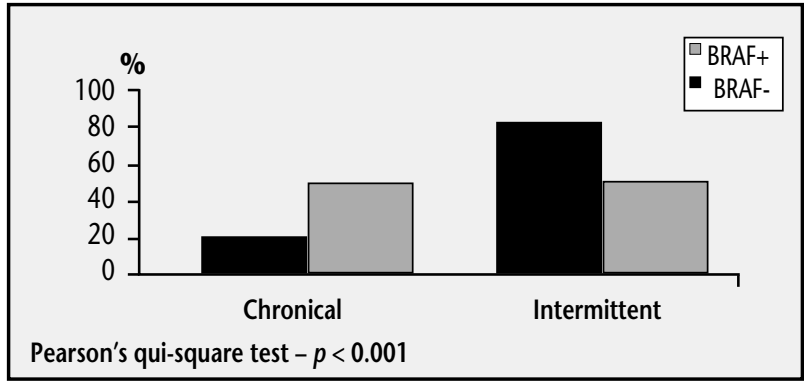

Figura 2 - Localization of melanomas according to sun exposure and BRAF mutations

\section{Correlation of BRAF mutations with histological parameters}

No association between BRAF mutations and other histological prognostic factors used for prognostic assessment such as Clark's level, number of mitosis, presence of ulceration, regression and satellitosis could be identified.

\section{Correlation of BRAF mutations with outcome}

We did not find any significant association or trend between presence of BRAF mutations in primary melanomas and clinical outcome (Figure 3) and overall disease free survival (Figure 4).

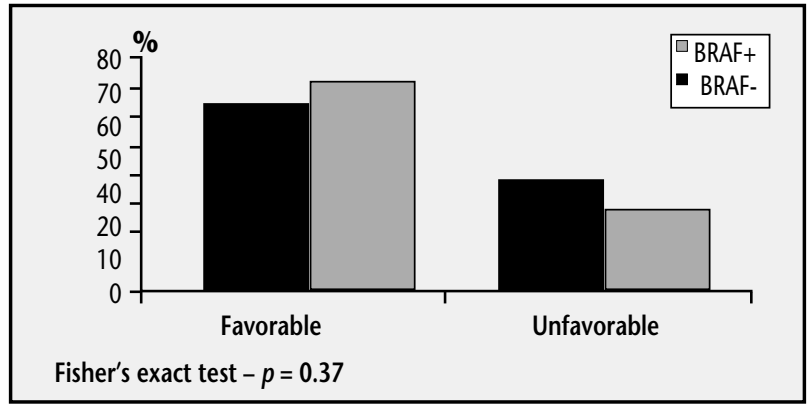

Figura 3 - Association between clinical outcome and BRAF mutations

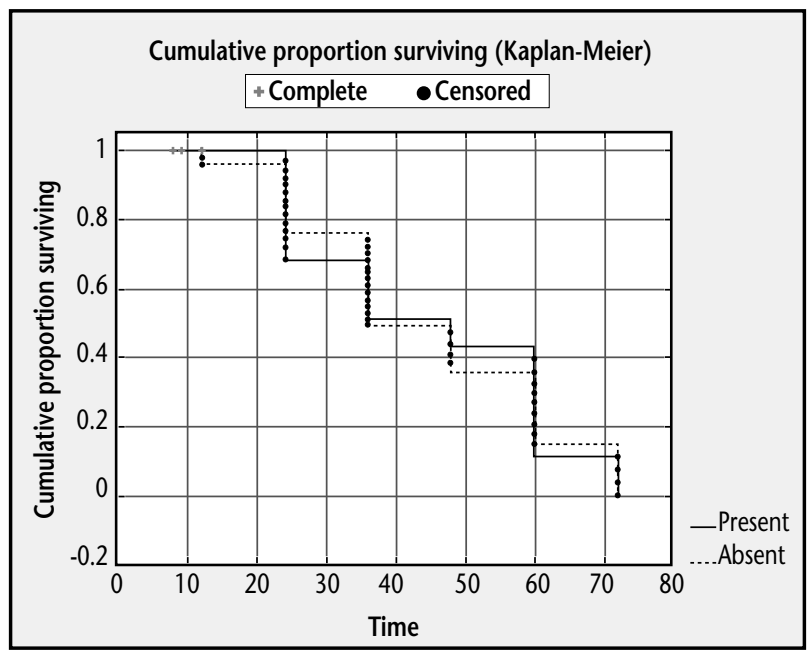

Figura 4 - Survival curve of Kaplan-Meier comparing the presence and absence of BRAF mutations ( $\mathrm{p}=0.93$ )

\section{Frequency of c-Kit mutation}

The melanoma specimens were also assessed for C-Kit L576P mutation, which was not identified in any case (0\%). In four cases, normal cells from the same individual were also analyzed for this mutation and no one was found. Four samples failed to amplify and, from these, three also could not be assessed for BRAF mutation.

\section{Discussion}

The purpose of this study was to clarify the incidence of BRAF oncogene and c-Kit mutations in primary cutaneous melanomas of the Brazilian population, their relation to tumor progression, and their possible effect on disease outcome. The results of the present study show a relative low frequency of BRAF mutation (39\%) in primary and metastatic (40\%) melanomas. This frequency is slightly lower than reported in other studies ${ }^{(5,10,11,14,17,24,25)}$, but lower frequencies of BRAF mutation than that we found have also been reported $(6-8,13,15,18,20-22)$. The Val599Glu substitution accounted for $92.1 \%$ (35 of 38) of all mutations, similar to previous reports, where the vast majority of BRAF

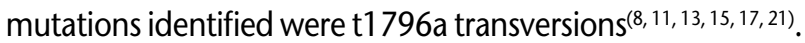
In contrast to our own investigation, which included a total of 96 melanomas, most studies published in the literature included less than 60 samples. As far as we know, this is the largest cohort of patients from Brazil analyzed for BRAF mutations. Due to the low frequency of BRAF mutation in the present study, we believe that this mutation alone is not responsible for melanoma development.

According to our findings, BRAF mutations seem to be related to initiation rather than to progression of melanoma because BRAF mutations present in primary lesions were always preserved in the corresponding metastatic lesions, similar to other studies that also characterized BRAF mutations as an early event in primary melanoma progression, because the same mutations detected in VGP melanomas were also present in corresponding RGP melanomas ${ }^{(14,17)}$. In four of our cases, the paired primary and metastatic lesions had the same BRAF genotype. This finding is in keeping with the suggestion of some investigators that BRAF mutation most likely occurs before melanoma metastasis ${ }^{(17)}$. In our own cases, no BRAF mutations arose at the metastatic stage, if the primary tumor was wild type for BRAF with the exception of two cases, in which the mutation occurred only in the metastasis, suggesting that it developed during tumor progression. Another 
interpretation would be that the mutations probably were present in the primary lesions of these patients, but only in minor subclones, that were too small to be detected by current methods ${ }^{(17)}$.

Most studies on BRAF mutations in melanoma available to date do not show significant correlation between BRAF mutation to any clinical or histological parameters, including gender, age at diagnosis, clinical stage at diagnosis, histogenic type of melanoma, level of tumor invasion according to Clark, tumor thickness, ulceration, site of first recurrence or overall survival ${ }^{(14,17,20,22,24)}$. In our study of melanomas from Brazilian patients, BRAF mutation was related to younger age of patients and an association with the pattern of sun exposure could be identified, BRAF mutations being more frequent in melanomas arising in skin subject to intermittent sun exposure. However, BRAF mutations did not correlate with any histological prognostic factor.

It is premature to state that age plays a significant role in BRAF mutation acquisition. Larger studies will be needed to validate this data. Melanoma in younger patients is often thought to be caused by genetic and intrinsic factors and recent studies on familial melanoma have demonstrated that there was no evidence of germ-line BRAF mutations in exon 15 , thus BRAF is unlikely to be a susceptibility gene for melanoma ${ }^{(12)}$.

While some authors speculated that UV radiation may induce BRAF mutations, our data seems to indicate that BRAF mutations are not particularly increased by chronic exposure to UV radiation and may not be related to UV radiation at all. This is in keeping with previous observations that concluded that BRAF mutation is not directly induced by UV exposure ${ }^{(22)}$ and that the relationship between cutaneous melanoma occurrence and UV exposure is complex and poorly understood since there is no clear relationship between dose and response ${ }^{(15)}$. In this context it also should be taken into account that BRAF mutations are seen in some internal malignancies, such as thyroid papillary carcinoma, colorectal carcinoma, pancreatic carcinoma, and borderline ovarian tumors, demonstrating that there are other factors apart from UV exposure that lead to the BRAF mutation. Furthermore, the $\mathrm{CC}$ to $\mathrm{TT}$ or $\mathrm{C}$ to $\mathrm{T}$ transitions, which occur in the $\mathrm{p} 53$ gene in non-melanoma skin cancers following exposure to ultraviolet light were not detected in any of the investigated melanomas.

The majority of studies which investigated c-Kit mutations report the immunohistochemical expression of this marker and did not perform the molecular analysis of the gene. Only three studies ${ }^{(4,28,29)}$, analysed the presence of both mutations, BRAF and c-Kit, in cutaneous melanomas but they did not correlate their results with clinical or histological prognostic factors. In our own investigation, none of the melanoma specimens studied expressed a C-Kit L576P mutation. Inclusion of a C-Kit L576P positive adenocarcinoma sample excluded the possibility of a methodical error. The low frequency of c-Kit L576P mutations in melanomas is in keeping with previous reports ${ }^{27,29)}$ which found c-Kit L576P mutations in up to $2 \%$ of melanomas. Because of the lack of C-Kit L576P mutations in our sample, prognostic implications of this molecular marker could not be studied. Pathogenetically, c-Kit L576P mutations do not seem to play a crucial role in the melanomas investigated here even though the lack of c-Kit gene expression does not exclude an early mutation in the c-Kit gene with subsequent down-regulation of gene expression. None of our patients, however, would have benefitted from imatinib therapy, a c-Kit inhibitor that has been remarkably successful in the treatment of patients with c-Kit mutation-positive gastrointestinal tumours.

We conclude that identification of both, BRAF and c-Kit mutation, do not serve as an indicator of prognosis in melanomas of Brazilian patients. The presence of BRAF mutation does not correlate with disease outcome or with any indicator of prognosis, such thickness, mitotic rate, ulceration, or regression, and c-Kit mutation seems to be a rare finding in melanomas. Moreover, the relatively low frequency of BRAF mutations (less than 50\%) in the melanomas studied by us calls into question whether this mutation really plays a key role in pathogenesis of melanoma of Brazilian patients. In fact, there must be alternative genetic pathways in development melanoma and BRAF mutation represents only one of many possible genetic alterations that may contribute to melanoma development.

\section{References}

1. ACKERMANN, A. B. Malignant melanoma. A unifying concept. Am J Dermatopatol, v. 2, n. 4, p. 309-13, 1980.
2. ALEXEEV, V.; YOON, K. Distinctive role of the cKit receptor tyrosine kinase signaling in mammalian melanocytes. J Invest Dermatol, v. 126, p. 1102-10, 2006. 
3. BALCH, C. M. et al. An evidence-based staging system for cutaneous melanoma. Cancer J Clin, v. 54, p. 131-49, 2004.

4. CURTIN, J. A. et al. Somatic activation of KIT in distinct subtypes of melanoma. J Clin Oncol, v. 24, n. 26, p. 4340-6, 2006.

5. DAVIES, H. et al. Mutations of the BRAF gene in human cancer. Nature, v. 417, p. 949-54, 2002.

6. DEICHMANN, M. et al. B-raf exon 15 mutations are common in primary melanoma ressection specimens but not associated with clinical outcome. Oncology, v. 66, p. 411-9, 2004.

7. DEICHMANN, M. et al. The oncogenic B-raf V599E mutation occurs more frequently in melanomas at sun-protected body sites. Int J Oncol, v. 29, p. 139-45, 2006.

8. DONG, J. et al. BRAF oncogenic mutations correlate with progression rather than initiation of human melanoma. Cancer Research, v. 63, p. 3883-5, 2003.

9. FRANCKEN, A. B. et al. The prognostic importance of tumor mitotic rate confirmed in 1317 patients with primary cutaneous melanoma and long follow-up. Ann Surg Oncol, v. 11, p. 426-33, 2004.

10. GOEL, V. K. et al. Examination of mutations in BRAF, NRAS, and PTEN in primary cutaneous melanoma. J Invest Dermatol, v. 126, p. 154-60, 2006.

11. GOYDOS, J. S. et al. Detection of B-RAF and N-RAS mutations in human melanoma. J Am Coll Surg, v. 3, p. 362-70, 2005.

12. LANG, J. et al. Abscence of exon 15 BRAF germline mutations in familial melanoma. Hum Mutat, v. 21, p. 327-30, 2003.

13. LANG, J.; MACKIE, R. M. Prevalence of exon 15 BRAF mutations in primary melanoma of the superficial spreading, nodular, acral, and lentigo maligna subtypes. J Invest Dermatol, v. 125, p. 575-9, 2005.

14. LIBRA, M. et al. Analysis of BRAF mutation in primary and metastatic melanoma. Cell Cycle, v. 4, n. 10, p. 1382-4, 2005.

15. MALDONADO, J. L. et al. Determinants of BRAF mutations in primary melanomas. J Nat Cancer Inst, v. 95, n. 24, p. 1878-80, 2003.

16. MASSI, G.; LEBOIT, P. E. Histological diagnosis of nevi and melanoma. Berlin: Steinkopf Verlag Darmstadt, 2004.
17. OMHOLT, K. et al. NRAS and BRAF mutations arise early during melanoma pathogenesis and are preserved throughout tumor progression. Clin Cancer Res, v. 9, n. 15, p. 6483-8, 2003.

18. POYNTER, J. N. et al. BRAF and NRAS mutations in melanoma and melanocytic nevi. Melanoma Res, v. 16, n. 4, p. 267-73, 2006.

19. RICANIADIS, N. et al. Long-term prognostic significance of HSP-70, c-myc and HLA-DR expression in patients with malignant melanoma. Eur J Surg Oncol, v. 1, n. 27, p. 88-93, 2001.

20. SALDANHA, G. et al. Cutaneous melanoma subtypes show different BRAF ans NRAS mutation frequencies. Hum Cancer Biol, v. 12, n. 15, p. 4499-505, 2006.

21. SASAKI, Y. et al. BRAF point mutations in primary melanoma show different prevalences by subtype. J Invest Dermatol, v. 123, p. 177-83, 2004.

22. SHINOZAKI, M. et al. Incidence of BRAF oncogene mutation and clinical relevance for primary cutaneous melanoma. Clin Cancer Res, v. 10, p. 1753-7, 2004.

23. SMYTH, P. et al. ret/PTC and BRAF act as distinct molecular, time dependant triggers in a sporadic Irish cohort of papillary thyroid carcinoma. Int J Surg Pathol, v. 13, n. 1, p. 1-8, 2005.

24. THOMAS, N. E. et al. Tandem BRAF mutations in primary invasive melanomas. J Invest Dermatol, v. 122, p. 1245-50, 2004.

25. VIROS, A. et al. Improving melanoma classification by integrating genetic and morphologic features. PloS Medicine, v. 5, n. 6, p. e120, 2008.

26. WEINLICH, G. et al. Metallothionein overexpression as a prognostic factor for progression and survival in melanoma. A prospective study on 520 patients. British J Dermatol, v. 149, n. 3, p. 535-41, 2003.

27. WENT, P. T. et al. Prevalence of KIT expression in human tumors. J Clin Oncol, v. 22, p. 4514-22, 2004.

28. WILLMORE-PAYNE, C. et al. BRAF and c-Kit gene copy number in mutation-positive malignant melanoma. Hum Pathol, v. 37, p. 520-7, 2006.

29. WILLMORE-PAYNE, C. et al. Human malignant melanoma: detection of BRAF and C-Kit activating mutations by high-resolution amplicon melting analysis. Hum Pathol, v. 36, n. 5, p. 486-93, 2005.

\begin{tabular}{l|l} 
& Mailing adress \\
\hline & Juliana Elizabeth Jung \\
Hospital Erasto Caertner \\
Serviço de Anatomia Patológica \\
Rua Ovande do Amaral, 20 - Jardim das Américas \\
CEP: 81520-060 - Curitiba-PR \\
Tel.: (41) 3361-5000 \\
Fax: (41) 3266-1822 \\
e-mail: julianajung@onda.com.br
\end{tabular}

